\title{
High Rate of Simian Immunodeficiency Virus (SIV) Infections in Wild Chimpanzees in Northeastern Gabon
}

\author{
Vanina Boué ${ }^{1,2}$, Sabrina Locatelli ${ }^{1}$, Floriane Boucher ${ }^{1,2}$, Ahidjo Ayouba ${ }^{1}$, Christelle Butel ${ }^{1}$, \\ Amandine Esteban ${ }^{1}$, Alain-Prince Okouga ${ }^{2}$, Alphonse Ndoungouet ${ }^{2}$, Peggy Motsch ${ }^{2}$, \\ Guillaume Le Flohic ${ }^{2}$, Paul Ngari ${ }^{2}$, Franck Prugnolle ${ }^{2,3}$, Benjamin Ollomo ${ }^{2}$, François Rouet ${ }^{2,4}$ \\ and Florian Liégeois $1,2, \dagger, *$
}

Received: 21 July 2015 ; Accepted: 25 August 2015 ; Published: 15 September 2015

Academic Editor: Andrew Mehle

1 UMI 233 "TransVIHMI", IRD / UM-INSERM U1175/ UM1, 34394 Montpellier, France; svetnina@yahoo.fr (V.B.); sabrina.locatelli@ird.fr (S.L.); floriane.boucher@wanadoo.fr (F.B.); ahidjo.ayouba@ird.fr (A.A.); christelle.butel@ird.fr (C.B.); amandine.esteban@ird.fr (A.E.)

2 Centre International de Recherches Médicales, BP 769 Franceville, Gabon; aokouga@yahoo.com (A.-P.O.); alphonsendoungouet@gmail.com (A.N.); p.motsch@yahoo.fr (P.M.); leflohg@yahoo.fr (G.L.F.); paul_ngari@yahoo.fr (P.N.); franck.prugnolle@ird.fr (F.P.); bollomo@yahoo.fr (B.O.); franrouet@yahoo.fr (F.R.)

3 Laboratoire Maladies Infectieuses et Vecteurs: Ecologie, Génétique, Evolution, Contrôle, UMR 224 IRD/CNRS/UM1, 34394 Montpellier, France

4 Institut Pasteur du Cambodge, Phnom-Penh BP 983, Royaume du Cambodge

* Correspondence: florian.liegeois@ird.fr.; Tel.: +33-0467415114; Fax: +33-0467416239

$\dagger$ Current affiliation: Laboratoire Maladies Infectieuses et Vecteurs: Ecologie, Génétique, Evolution, Contrôle, UMR 224 IRD/CNRS/UM1, 34394 Montpellier, France

\begin{abstract}
The emergence of HIV-1 groups $\mathrm{M}, \mathrm{N}, \mathrm{O}$, and $\mathrm{P}$ is the result of four independent cross-species transmissions between chimpanzees (cpz) and gorillas (gor) from central/south Cameroon and humans respectively. Although the first two SIVcpz were identified in wild-born captive chimpanzees in Gabon in 1989, no study has been conducted so far in wild chimpanzees in Gabon. To document the SIVcpz infection rate, genetic diversity, and routes of virus transmission, we analyzed 1458 faecal samples collected in 16 different locations across the country, and we conducted follow-up missions in two of them. We found 380 SIV antibody positive samples in 6 different locations in the north and northeast. We determined the number of individuals collected by microsatellite analysis and obtained an adjusted SIV prevalence of $39.45 \%$. We performed parental analysis to investigate viral spread between and within communities and found that SIVs were epidemiologically linked and were transmitted by both horizontal and vertical routes. We amplified pol and gp 41 fragments and obtained 57 new SIVcpzPtt strains from three sites. All strains, but one, clustered together within a specific phylogeographic clade. Given that these SIV positive samples have been collected nearby villages and that humans continue to encroach in ape's territories, the emergence of a new HIV in this area needs to be considered.
\end{abstract}

Keywords: Chimpanzee; SIV; AIDS; Africa; antibody; microsatellite; primate; prevalence; retrovirus; transmission

\section{Introduction}

The four groups of Human Immunodeficiency Virus Type 1 known to date (HIV-1 M, N, O and $\mathrm{P})$ are the result of four independent cross-species transmission events between apes and humans in west-central Africa [1-5]. During the last decade, the development of serological techniques 
and the improvement of viral RNA amplification in faecal samples provided the possibility to perform large-scale studies on wild great apes across equatorial Africa, as previously demonstrated in Cameroon, Democratic Republic of Congo (DRC) and Tanzania [4-7]. These studies brought to light the origins of HIV-1 group $\mathrm{M}$ and $\mathrm{N}$ in chimpanzees (Pan troglodytes troglodytes (Ptt)), infected with SIVcpzPtt [1] and HIV-1 group O and P in gorillas (Gorilla gorilla gorilla), infected with SIVgor [2,3] from Cameroon. The long-term monitoring of habituated chimpanzee communities from east Africa (Pan troglodytes schweinfurthii (Pts)) revealed that chimpanzees infected with SIVcpzPts could develop an AIDS-like pathology [8]. SIV infects more than 45 species of Non-Human Primates (NHP) living in Africa $[9,10]$ but the view that SIV is apathogenic in all of their natural hosts [11] has been challenged by studies showing that chimpanzees naturally infected with SIV do develop an AIDS-like syndrome [12-14]. These findings provided compelling evidence that SIVcpz has a substantial negative impact on the health, reproduction and lifespan of chimpanzees in the wild $[8,12]$.

The SIVcpzPtt ancestors of HIV-1 group $\mathrm{M}$ and $\mathrm{N}$ have been isolated from chimpanzees inhabiting southeastern Cameroon (close to the Central African Republic (CAR) border) and south-central Cameroon (inside the Dja reserve), respectively [1]. The closest relatives of HIV-1 group $\mathrm{O}$ and $\mathrm{P}$ are SIVgor strains from wild-living gorillas inhabiting central and southwest Cameroon, respectively [2,3]. Group M, the HIV-1 pandemic form, has so far infected at least 60 million people and caused more than 25 million deaths [15], whereas groups $\mathrm{N}$ and $\mathrm{P}$ are found exclusively in Cameroon with only a few infected individuals $[16,17]$. HIV-1 group $\mathrm{O}$ is mainly present in west Central Africa with low prevalence rates ( $<0.5 \%$ of HIV infected individuals) [18-20].

There are four chimpanzee subspecies [21]. However, only two of them-Pan troglodytes troglodytes, ranging from Cameroon, south of the Sanaga River, to the Congo River/Ubangi River (DRC) and Pan troglodytes schweinfurthii, ranging from the Ubangi River/Congo River in CAR and DRC, to western Uganda, Rwanda and western Tanzania - are infected with SIVcpzPtt and SIVcpzPts, respectively [22]. SIVcpz infections are absent in the other two chimpanzee subspecies [5,23,24], Pan troglodytes verus from West Africa and Pan troglodytes ellioti inhabiting Nigeria and western Cameroon, north of the Sanaga River [25]. Past studies showed that SIVcpz infecting neighboring populations is phylogenetically interspersed, whereas chimpanzee populations that are separated by major geographical barriers (such as rivers) or by long distances are infected with SIVcpz belonging to distinct lineages $[1,5]$.

SIVcpz infection rate is unevenly distributed, ranging from $30 \%$ to $50 \%$ in certain communities, whereas other communities are uninfected $[1,5,26]$. It must be pointed out that sampling did not cover all regions in Africa where chimpanzees live and many areas remain today totally unexplored. For instance, no study on SIV in wild chimpanzees has been conducted in Gabon (Gab) despite the fact that the first characterized SIVcpzPtt strains were isolated in the north and eastern part of this country at the end of the 1980s. They were named SIVcpzGab-1 and Gab-2 [27,28]. More recently, a third SIVcpz strain, SIVcpzGab-4, was described in a wild-born chimpanzee held captive at the Centre International de Recherches Médicales de Franceville (CIRMF) [29]. In addition, information about SIV infections in other sympatric NHP populations is also scarce: a recent study highlighted the presence of SIV infection in red capped mangabeys (Cercocebus torquatus), mandrills (Mandrillus sphinx) and moustached monkeys (Cercopithecus cephus) bushmeat collected at local markets in Gabon [30,31]. Before the above-mentioned study, a semi-free ranging population of mandrills has been studied in Gabon for SIV infection and its patterns of transmission [32,33].

The aims of this study where therefore to (1) conduct the first large-scale survey in Gabon to further document the prevalence and genetic diversity of the SIV virus infecting wild chimpanzee populations, and (2) determine the routes of viral transmission and estimate their spread across territories by investigating the parental links among and between groups. 


\section{Materials and Methods}

\subsection{Study Sites and Chimpanzee Faecal Samples Collection}

Between September 2009 and June 2013, we collected faecal samples from wild chimpanzees living in remote primary forests and in secondary forests surrounding villages in Gabon, north and south of the Ogooue River (Figure 1). Northeast of the river, we collected stool specimens outside of villages built along the trail connecting Odjala village (OD) to Malouma village (ML). The distance between OD and Makatamangoye 2 (MA) and MA and Iyoko milieu (IY) is about $30 \mathrm{~km}$, walking-distance, whereas IY and ML are located approximately $60 \mathrm{~km}$ apart (straight line) (Figure 1).

We collected faecal samples underneath night nests or on track. We recorded GPS positions and estimated the time of faecal deposition, by assessing the texture, stage of decomposition and presence of flies on the dung. We inferred the species origin in the field according to shape, size and texture of the faecal samples as well as presence of footprints or nests nearby. We collected about $20 \mathrm{~g}$ of dung in a $50 \mathrm{~mL}$ tube, containing $20 \mathrm{~mL}$ of RNAlater $\AA$ (Ambion, Austin, TX, USA), and we kept samples at ambient temperature at base camp, for a maximum of three weeks. Samples were then stored at $-80^{\circ} \mathrm{C}$ in Franceville, Gabon.

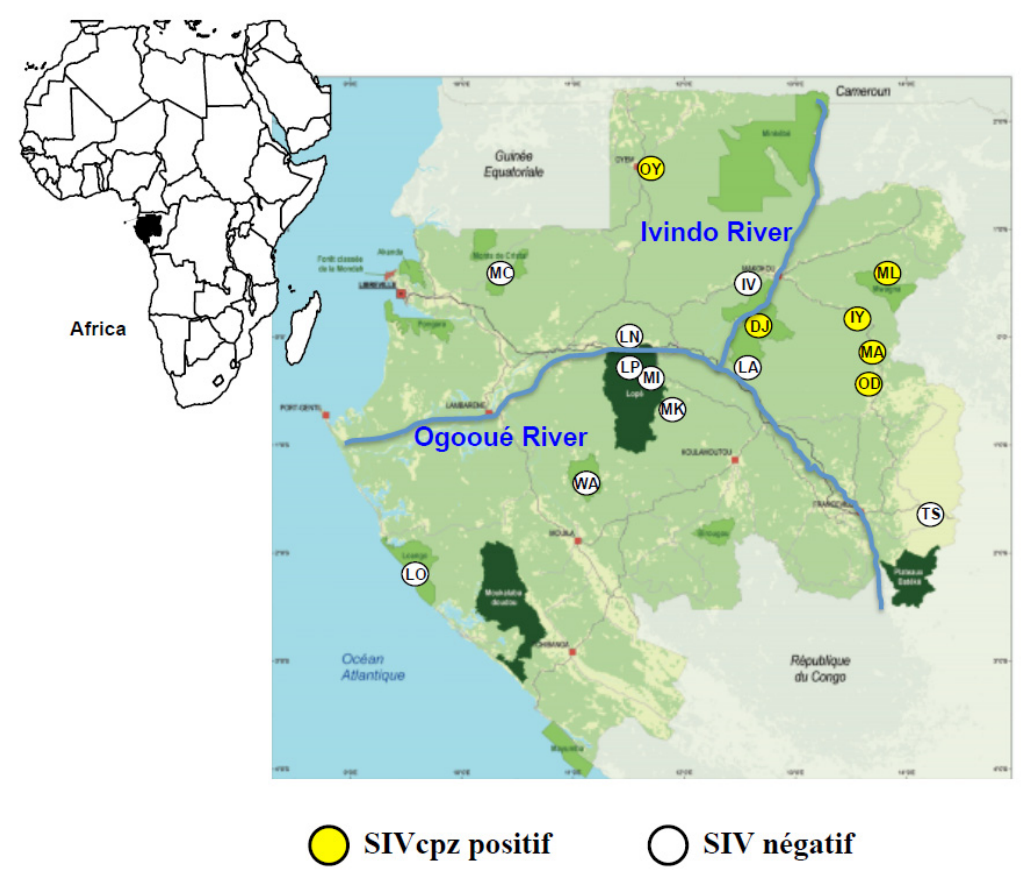

Figure 1. Geographical distribution of chimpanzee faecal samples collection sites (white and yellow circles) from Gabon Locations of faecal samples collection: LO = Louango, WA = Waka, MK = Makande, MI = Mikongo, LP = Lopé National Park, LN = Lopé SEGC site, MC = Monts de Cristal, OY = Oyem, IV = Ivindo, DJ = Djidji, LA = Langoué, TS = Tsouba, OD = Odjala, Ma = Makatamangoye, IY = Iyoko milieu, ML = Malouma. Yellow circles represent sites where SIVcpz positive samples were identified.

All NHP samples were obtained with the authorization of the Provincial Inspections of Water and Forests and the Centre National de la Recherche Scientifique et Technologique (CENAREST, AR0031/09, AR0006/11).

\subsection{Detection of SIVcpz Antibodies in Chimpanzee Faecal Samples}

All faecal samples were tested for the presence of HIV-1 cross-reactive antibodies using the INNO-LIA ${ }^{\circledR}$ HIV I/II score Confirmation test (Fujirebio, Courtaboeuf, France), as previously 
described [34]. This test contains HIV-1 and HIV-2 recombinant proteins and synthetic peptides coated as discrete lines on a nylon strip. These antigens can cross-react with SIV antibodies present in the sample. Faecal samples stored in RNAlater ${ }^{\circledR}$ must undergo dialyses before IgG antibodies can be recovered. We therefore applied dialysis methods previously adopted for antibody detection in fecal samples from gorillas and chimpanzees [1,2]. We performed all assays according to the manufacturer's instructions. Samples were scored as INNO-LIA positive when they reacted with $\geqslant 1$ HIV antigen.

\subsection{DNA and RNA Extraction from Chimpanzee Faecal Samples}

We used a QIAamp Stool DNA Mini kit (Qiagen, Valencia, CA, USA) to extract fecal DNA for species confirmation and microsatellite analyses, as published elsewhere [1]. Briefly, $2.0 \mathrm{~mL}$ of fecal RNAlater ${ }^{\circledR}$-preserved sample were re-suspended in stool lysis buffer, clarified by centrifugation, treated with an InhibitEx tablet, and proteinase K, and passed through a DNA binding column. Bound DNA was eluted in 100-200 $\mu \mathrm{L}$ of elution buffer.

Faecal RNA was extracted using the NucliSens Magnetic Extraction kit (Biomérieux, Craponne, France), which utilizes magnetic silica particles to purify RNA [35] following the same protocol steps adopted in previous studies [7]. Briefly, $2.0 \mathrm{~mL}$ of sample were vortexed with $7.0 \mathrm{~mL}$ of NucliSens Lysis buffer for $1 \mathrm{~min}$. Samples were then incubated at room temperature for $1-2 \mathrm{~h}$ and centrifuged at $4000 \mathrm{rpm}$ for $30 \mathrm{~min}$. Supernatant were filtered and centrifuged at $4500 \mathrm{rpm}$ for $5 \mathrm{~min}$. We then followed the magnetic extraction procedure according to the manufacturer instructions to obtain a final elution volume of $50 \mu \mathrm{L}$ fecal RNA.

\subsection{Species Determinations}

The species was confirmed by mtDNA analyses, as described previously $[1,2,36]$. Briefly, $5 \mu \mathrm{L}$ of extracted faecal DNA were used for mitochondrial DNA amplification. A 450 to 500bp mtDNA fragment spanning the hypervariable D loop was amplified from faecal DNA using primers L15997 and H16498 [37]. Differences in DNA amplicon weight allowed us to determine whether faecal samples were collected from gorillas (450bp) or chimpanzees (500bp). When the D-loop amplification failed, a 386bp fragment spanning the 12SrRNA gene was targeted, using primers 12S-L01091 and 12S-H01478 [37]. If both amplification strategies yielded no results, samples were considered degraded. The samples origin was assessed with the "Basic Local Alignment Search Tools" [38].

\subsection{Number of Collected Individuals}

In order to determine the number of collected individuals, we ran microsatellite analyses on all SIVcpz positive and negative faecal samples from OD, MA and IY and on a randomly selected number of samples from ML $(n=90)$ (Table 1). Samples were genotyped at seven autosomal microsatellite loci with two multiplex PCRs, according to the protocols used in previous studies $[4,7]$. For sex determination, a region in the amelogenin gene that contains a deletion in the $X$, but not in the $\mathrm{Y}$ chromosome was amplified [39]. We used the Taq DNA polymerase Core kit (MP Biomedical, Irvine, CA, USA) with 2 to $10 \mu \mathrm{L}$ fecal DNA. Homozygous loci were amplified from three to seven times to minimize problems associated with allelic dropout, which frequently occurs when genotyping low-yield DNA samples [40]. All PCR reactions included negative control samples for quality assurance. We analyzed each multiplex PCR product on an ABI 3130 capillary array genetic analyzer (Applied Biosystems, Foster City, CA, USA). We determined fragment sizes against a Genescan 600 Liz size standard (Applied Biosystems, Foster City, CA, USA), and allele sizes using the Genemapper ID version 4 software (Applied Biosystems, Foster City, CA, USA). We discarded all samples with unsuccessful amplification after five PCR attempts and two independent DNA extractions. We discarded from further analyses all samples that displayed an incomplete allelic profile (less than four loci), a multiple peak profile for the same locus, or discordant results. 
Table 1. Crude and corrected estimations of Simian Immunodeficiency Virus (SIV) infection rate in wild chimpanzees from different field sites in Gabon (2009-2013).

\begin{tabular}{|c|c|c|c|c|c|c|c|c|c|c|c|c|c|}
\hline \multirow[b]{2}{*}{$\begin{array}{l}\text { Collection } \\
\text { Sites }\end{array}$} & \multirow[b]{2}{*}{$\begin{array}{l}\text { Faecal } \\
\text { Samples } \\
\text { Collected }\end{array}$} & \multirow[b]{2}{*}{$\begin{array}{c}\text { SIVcpz } \\
\text { Antibody } \\
\text { Positive } \\
\text { Samples }\end{array}$} & \multirow[b]{2}{*}{$\begin{array}{l}\text { Estimated } \\
\text { Number } \\
\text { Of } \\
\text { Individuals } \\
\text { Collected }\end{array}$} & \multirow[b]{2}{*}{$\begin{array}{c}\text { Samples } \\
\text { Successfully } \\
\text { Genotyped/no } \\
\text { Genotyped }\end{array}$} & \multicolumn{4}{|c|}{ HIV Antibody Positive Profile } & \multicolumn{5}{|c|}{ HIV Antibody Negative Profile } \\
\hline & & & & & $\begin{array}{c}\text { Prevalence } \\
\text { Of SIVcpz } \\
\text { Antibody } \\
\text { Positive (\%) } \\
\text { Genotyped } \\
\text { Animals } \\
\text { (Individuals) }\end{array}$ & $\begin{array}{l}\text { vRNA } \\
\text { Positive } \\
\text { Genotyped } \\
\text { Animals } \\
\text { pol / env }\end{array}$ & $\begin{array}{l}\text { SIVcpz } \\
\text { Antibody } \\
\text { Positive } \\
\text { Samples }\end{array}$ & $\begin{array}{c}\text { Number } \\
\text { Of vRNA } \\
\text { Positive } \\
\text { Samples } \\
\text { pol / env }\end{array}$ & $\begin{array}{c}\text { Antibody } \\
\text { Negative } \\
\text { Samples } \\
\text { Tested } \\
\text { By PCR }\end{array}$ & $\begin{array}{c}\text { Number } \\
\text { Of } \\
\text { individuals } \\
\text { Tested By } \\
\text { PCR }\end{array}$ & $\begin{array}{l}\text { Number } \\
\text { Of vRNA } \\
\text { Positive } \\
\text { Individuals } \\
\text { pol / env }\end{array}$ & $\begin{array}{l}\text { Samples } \\
\text { Tested } \\
\text { By PCR }\end{array}$ & $\begin{array}{c}\text { Number } \\
\text { Of vRNA } \\
\text { Positive } \\
\text { Samples } \\
\text { pol / env }{ }^{D}\end{array}$ \\
\hline LP & 54 & 0 & & & & & & & & & & & \\
\hline MI & 194 & 0 & & & & & & & & & & & \\
\hline TS & 13 & 0 & & & & & & & & & & & \\
\hline MK & 11 & 0 & & & & & & & & & & & \\
\hline LA & 16 & 0 & & & & & & & & & & & \\
\hline MA & 608 & $263(44 \%)$ & 224 & $504 / 104$ & $103(46 \%)$ & $23 / 18$ & 44 & $6 / 4$ & 146 & 50 & $5 / 6$ & 23 & $2 / 1$ \\
\hline MC & 33 & 0 & & & & & & & & & & & \\
\hline IV & 19 & 0 & & & & & & & & & & & \\
\hline DJ & 40 & $8(20 \%)$ & & & & & & & & & & & \\
\hline ML & 181 & $85(47 \%)$ & 19 & $85 / 96$ & $12(63.5 \%)$ & $5 / 1$ & 47 & $5 / 2$ & & & & & \\
\hline WA & 18 & 0 & & & & & & & & & & & \\
\hline $\mathrm{LN}$ & 12 & 0 & & & & & & & & & & & \\
\hline OY & 78 & $1(1.3 \%)$ & & & & & & & & & & & \\
\hline IY & 31 & $18(58 \%)$ & 12 & $25 / 6$ & $4(33.3 \%)$ & $1 / 0$ & & & & & & & \\
\hline OD & 39 & $5(12.8 \%)$ & 17 & $35 / 4$ & $4(23.5 \%)$ & 0 & & & & & & & \\
\hline $\mathrm{LO}$ & 111 & 0 & & & & & & & & & & & \\
\hline Total & 1458 & $380(26,1)$ & 272 & $649 / 210$ & $123(41.6 \%)$ & $29 / 19$ & 91 & $11 / 6$ & 146 & 50 & $5 / 6$ & 23 & $2 / 1$ \\
\hline
\end{tabular}

A In MA and ML sites 11 and 1 SIV strains were both amplified in pol and env respectively. ${ }^{\mathbf{B}}$ In MA and ML site 2 and 2 SIV strains were both amplified in pol and env respectively.

C 5 SIV strains were both amplified in pol and env. ${ }^{D} 1$ strains were both amplified in pol and env. 
We used Cervus v3.0 (Field Genetics, London, UK) [41] to assess allele frequency, expected heterozygosity, polymorphic information content (PIC), Hardy-Weinberg (HW) equilibrium, to identify samples collected in MA, ML, IY and OD that have matching genotypes, and to determine the suitability of loci to run downstream analysis including parentage analysis. We checked all genotypes mismatching at one locus for allelic dropout [42] and we allowed an allelic mismatch at one locus, but only if it represented a missing allele. We gave a consensus ID to matching samples (Table S1 supplementary material). We calculated P(ID)HW for each individual (Data not shown). P(ID)HW is the probability that two individuals drawn at random from a population will have the same genotype at multiple loci, assuming that the loci we chose for these analyses are inherited independently (i.e., that they are unlinked). For parentage analysis, we assumed that we collected and successfully genotyped a quarter of the offspring in every group and a quarter of the candidate parents. The frequency of typing errors and the error rate in likelihood calculations were set at 0.01 . The minimum number of typed loci was set at four out of seven. Allele frequencies, critical to run simulations and to assess confidence of parentage assignment were also calculated. Confidence in assignment of parentage to the most likely candidate parent is evaluated relative to a critical threshold determined in the simulation (LOD score). To ensure satisfactory confidence in individual parentage assignments, we regarded $95 \%$ as a minimum value for the population confidence level set in Cervus.

\subsection{SIVcpz Partial pol, env and gp41-nef PCR Amplifications}

RT-PCR amplifications were done for all SIV antibody positive samples, as well as for some SIV negative antibody samples from the MA site. We first amplified partial pol (400 bp) and gp41 (450 bp) PCR fragments using consensus primers previously described (Table S2 supplementary material) [1]. In order to optimize our PCR amplification systems, we designed from the newly obtained pol and gp41 sequences more specific primers allowing the amplification of $150 \mathrm{bp}$ and $170 \mathrm{bp}$ in pol and gp41 respectively (Table S2). We then proceeded to amplify a larger PCR fragment (916 bp) spanning the end of gp41 and the first part of nef gene using a combination of specific and consensus primers (Table S2). In addition, we designed new consensus primers, which were used in combination with the specific primers to amplify a 365 and 325 bp nucleic acid fragments in pol and env, respectively (Table S2). For the first PCR round, bovine serum albumin (BSA) was added at the final concentration of $0.2 \mu \mathrm{g} / \mathrm{mL}$ to improve the success of amplification. All RT-PCR reactions were performed using the Expand Reverse transcriptase, and the Expand long Template PCR kit (Roche Diagnostics, Indianapolis, IN, USA), according to the manufacturer's instructions. After purification with the Geneclean Turbo Kit (Qbiogene, Inc., Carlsbad, CA, USA), PCR products were sequenced on an automated sequencer (3130xl Genetic Analyser, Applied Biosystems, Foster City, CA, USA). The resulting sequences were aligned with SEQMAN DNASTAR software (Lasergene, DNASTAR, Inc., Madison, WI, USA).

\subsection{Phylogenetic Analyses}

The partial nucleic acid sequences of the new SIVcpz strains were aligned using MEGA 5 [43] with minor manual adjustments. We excluded those sites that could not be unambiguously aligned. We inferred the phylogenies for the small pol and env fragments using the Neighbor-Joining method (implemented in Mega 5 with the K2P model of evolution), and the Maximum Likelihood (ML) method (implemented in PhyML) for the 916 bp gp41-nef fragment and the 365 and 325 bp nucleic acid fragment in pol and env, respectively [44]. We tested the reliability of branching orders using the bootstrap approach (1000 replicates). The suited evolution model $\left(\mathrm{GTR}+\Gamma_{4}+\mathrm{I}\right)$ used in the ML analyses was defined using Topali [45].

\subsection{Nucleotide Sequence Accession Numbers}

The new sequences have been deposited to the GenBank under the following accession numbers: KR150263 to KR150368. 


\section{Results}

\subsection{SIV Infection in Wild Chimpanzees in Gabon}

\subsubsection{Crude SIV Prevalence Rates in Wild Chimpanzee Faecal Samples}

Between 2009 and 2013, we collected 1458 faecal samples from wild chimpanzees in 16 different locations across Gabon (Figure 1). Five locations were south and 11 north of the Ogooué River (Figure 1). We confirmed by mtDNA analysis that all faecal samples collected were from chimpanzees. Among the 1458 chimpanzee faecal samples collected in six different locations in the north and northeast of the country, 380 samples were SIV antibody positive, yielding an overall prevalence rate of $26.1 \%(0 \%-58 \%)$ (Table 1$)$.

The SIVcpz antibody positive samples were unevenly distributed with prevalence rate oscillating between $1.3 \%$ and $58 \%$ according to the collection site (Table 1). In OY (north Gabon), only one specimen (on a total of 78 samples, for an infection rate of $1.3 \%$ ) cross-reacted weakly with the HIV p24 antigen (Table 1, Figure 1). In DJ (Ivindo National Park), eight of 40 samples (20\%) cross-reacted with HIV antigens (Table 1, Figure 1). The highest sero-prevalence rate was obtained in three sites located in the northeast: ML, IY and MA, with respectively $47 \%, 58 \%$ and $44 \%$ of SIV infections (Table 1, Figure 1). In addition, $12.8 \%$ of the samples collected in OD, which is located 30 $\mathrm{km}$ south of MA, tested positive for SIV antibodies and presented antibody profiles comparable to those observed in DJ, ML, IY and MA (Figure 2). The Inno-LIA patterns were HIV p24 alone or p24 + p17 or, p24 + p17 + gp41 (Figure 2).

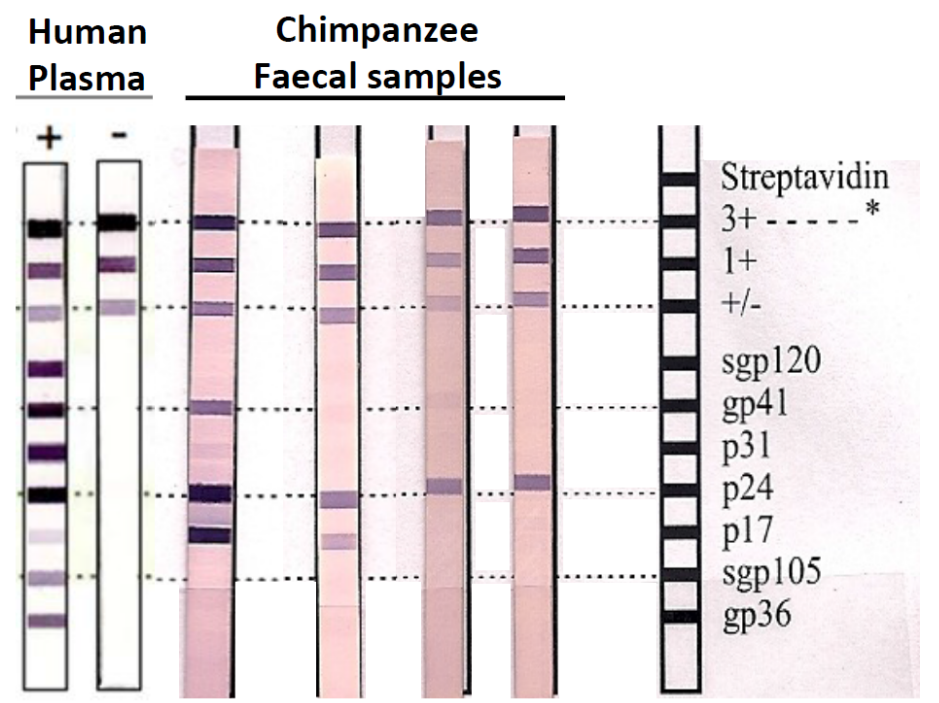

Figure 2. SIV antibody positive profiles. Example of HIV-1/HIV-2 cross-reactive antibodies profile in chimpanzee faecal samples using a line immunoassay (INNO-LIA HIV Confirmation, Innogenetics, Ghent, Belgium). Varying patterns of reactivity to HIV peptides and proteins (gp41, p24, p31 and p17) are shown. Plasma samples from HIV-1/HIV-2-negative and -positive persons are shown as controls on the left. The $3+, 1+$ and $+/-$ bands at the top of all test strips control for sample addition (presence of plasma immunoglobulin) and test performance (binding of secondary antibody).

\subsubsection{Adjusted SIV Prevalence Rates According to the Number of Collected Individuals}

To study more in detail the SIVcpz prevalence in chimpanzee communities from the northeast, 13 follow-up missions were conducted in MA and three in ML (Figure 3). From the 608 samples collected in MA, 504 samples were successfully genotyped, and corresponded to 224 individuals (Table 1). Microsatellite results were non-interpretable in the 104 remaining specimens. Thus, each 
chimpanzee was sampled 2.2 times. Among these 224 individuals, 103 were SIV antibody positive, leading to an infection rate of $46 \%$ (Figure 3, Table 1). Also, 39 of them were collected repeatedly (one to four times) during the various missions, within a 25 months period of time. Interestingly, the serological status of 10 out of 39 individuals was discordant (Table 2). For five animals (Mac-ID-010, $-054,-055,-056,-058,-077)$ the first sample tested negative, according to serological tests, whereas the subsequent samples tested positive. An initial positive serological result followed by a negative result was obtained in four animals. In addition, samples from the same individual (Mac-ID-025, $-044,-071,-150,-171)$ collected during the same field mission showed discordant serological results over time (Table 2). In ML, on 181 collected faecal samples (Table 1), 85 were successfully genotyped allowing 19 individuals to be identified. Each chimpanzee was thus sampled 4.5 times. Out of the 19 individuals, 12 were SIV antibody positive (63.5\%) (Figure 3, Table 1). In IY, on 25 collected and genotyped samples (Table 1), 12 individuals were identified, meaning that each animal was sampled 2.1 times. Four out of 12 individuals were SIV antibody positive (33.3 \%) (Figure 3, Table 1). In OD, 5 out of 39 faecal samples collected were SIV antibody positive (12.8\%) (Table 1). We genotyped them all and we obtained 17 individuals, with each animal sampled 2.3 times. Four out of 17 individuals were SIV antibodypositive (23.5\%) (Figure 3, Table 1).

Altogether, these results lead to a high SIV prevalence in wild chimpanzee communities from eastern Gabon, with a mean corrected infection rate of $39.45 \%$ ( $23.5 \%-55 \%)$.

Table 2. Discordant serological test results in samples from the same individual.

\begin{tabular}{|c|c|c|c|c|c|c|}
\hline & $\mathrm{ID}^{\mathrm{a}}$ & $\begin{array}{l}\text { Field } \\
\text { Number }\end{array}$ & $\begin{array}{c}\text { Date of } \\
\text { Sampling }\end{array}$ & $\begin{array}{l}\text { SIV Serological } \\
\text { Test }^{\text {b }}\end{array}$ & \multicolumn{2}{|c|}{ GPS Points } \\
\hline \multirow{32}{*}{$\begin{array}{l}\text { Samples } \\
\text { collected } \\
\text { during } \\
\text { different } \\
\text { field } \\
\text { missions }\end{array}$} & \multirow{2}{*}{ MA-ID-010 } & Gab-0902 & $07 / 04 / 11$ & neg & $\mathrm{S} 00^{\circ} 08.276$ & $\mathrm{E}^{2} 13^{\circ} 38.105$ \\
\hline & & Gab-1001 & $17 / 05 / 11$ & pos & \multicolumn{2}{|c|}{$\begin{array}{c}8 \mathrm{Km} \text { to the west from MA } \\
\text { village }\end{array}$} \\
\hline & \multirow[t]{2}{*}{ MA-ID-028 } & Gab-1012 & $20 / 05 / 11$ & pos & \multicolumn{2}{|c|}{$\begin{array}{c}8 \mathrm{Km} \text { to the west from MA } \\
\text { village }\end{array}$} \\
\hline & & Gab-2092 & 08/07/12 & neg & $\mathrm{S} 00^{\circ} 08.170$ & E0133․ 366 \\
\hline & \multirow[t]{9}{*}{ MA-ID-036 } & Gab-1227 & $04 / 11 / 11$ & pos & S00 ${ }^{\circ} 07.707$ & ${\mathrm{E} 013^{\circ} 31.226}$ \\
\hline & & Gab-1228 & $04 / 11 / 11$ & pos & $\mathrm{S} 00^{\circ} 07.707$ & $\mathrm{E}^{2} 13^{\circ} 31.226$ \\
\hline & & Gab-1229 & $04 / 11 / 11$ & pos & $\mathrm{S} 00^{\circ} 07.707$ & $\mathrm{E} 013^{\circ} 31.226$ \\
\hline & & Gab-1230 & $04 / 11 / 11$ & pos & $\mathrm{S} 00^{\circ} 07.707$ & $\mathrm{E} 013^{\circ} 31.226$ \\
\hline & & Gab-1510 & $11 / 03 / 12$ & pos & $\mathrm{S} 00^{\circ} 06.500$ & $\mathrm{E} 013^{\circ} 31.722$ \\
\hline & & Gab-1513 & $11 / 03 / 12$ & pos & $\mathrm{S} 00^{\circ} 06.397$ & $\mathrm{E} 013^{\circ} 31.777$ \\
\hline & & Gab-1515 & $11 / 03 / 12$ & neg & $\mathrm{S}^{\circ} 0^{\circ} 06.397$ & $\mathrm{E}^{2} 13^{\circ} 31.777$ \\
\hline & & Gab-1517 & $11 / 03 / 12$ & pos & $\mathrm{S} 00^{\circ} 06.335$ & $\mathrm{E} 013^{\circ} 31.788$ \\
\hline & & Gab-1518 & $11 / 03 / 12$ & pos & $\mathrm{S} 00^{\circ} 06.264$ & $\mathrm{E} 013^{\circ} 31.792$ \\
\hline & \multirow[t]{7}{*}{ MA-ID-054 } & Gab-0923 & $07 / 04 / 11$ & neg & $\mathrm{S} 00^{\circ} 08.093$ & $\mathrm{E}^{013^{\circ}} 36.047$ \\
\hline & & Gab-0924 & $07 / 04 / 11$ & neg & $\mathrm{S} 00^{\circ} 08.093$ & $\mathrm{E} 013^{\circ} 36.047$ \\
\hline & & Gab-1283 & $01 / 12 / 11$ & pos & $\mathrm{S} 00^{\circ} 07.800$ & $\mathrm{E} 013^{\circ} 35.962$ \\
\hline & & Gab-1288 & $01 / 12 / 11$ & pos & $\mathrm{S}^{\circ} 0^{\circ} 07.890$ & $\mathrm{E}^{2} 13^{\circ} 36.116$ \\
\hline & & Gab-1289 & $01 / 12 / 11$ & pos & $\mathrm{S} 00^{\circ} 07.891$ & $\mathrm{E}^{2} 13^{\circ} 36.128$ \\
\hline & & Gab-1295 & $01 / 12 / 11$ & pos & $\mathrm{S} 00^{\circ} 08.002$ & E013.36.262 \\
\hline & & Gab-1321 & $03 / 12 / 11$ & pos & $\mathrm{S} 00^{\circ} 08.832$ & $\mathrm{E} 013^{\circ} 35.001$ \\
\hline & \multirow[t]{3}{*}{ MA-ID-055 } & Gab-0926 & $07 / 04 / 11$ & neg & $\mathrm{S} 00^{\circ} 08.193$ & ${\mathrm{E} 013^{\circ} 34.907}^{\circ}$ \\
\hline & & Gab-1293 & $01 / 12 / 11$ & pos & $\mathrm{S} 00^{\circ} 07.992$ & $\mathrm{E} 013^{\circ} 36.273$ \\
\hline & & Gab-1294 & $01 / 12 / 11$ & pos & $\mathrm{S} 00^{\circ} 07.986$ & $\mathrm{E} 013^{\circ} 36.264$ \\
\hline & \multirow[t]{2}{*}{ MA-ID-056 } & Gab-0922 & $07 / 04 / 11$ & neg & $\mathrm{S} 00^{\circ} 08.093$ & $\mathrm{E}^{013^{\circ}} 36.047$ \\
\hline & & Gab-1297 & $01 / 12 / 11$ & pos & $\mathrm{S} 00^{\circ} 08.086$ & $\mathrm{E}^{2} 13^{\circ} 36.337$ \\
\hline & \multirow[t]{5}{*}{ MA-ID-058 } & Gab-0915 & $13 / 04 / 11$ & neg & $\mathrm{S} 00^{\circ} 07.276$ & $\mathrm{E}^{0} 13^{\circ} 35.538$ \\
\hline & & Gab-0929 & $08 / 04 / 11$ & neg & $\mathrm{S} 00^{\circ} 08.552$ & ${\mathrm{E} 013^{\circ} 34.845}$ \\
\hline & & Gab-1314 & $02 / 12 / 11$ & pos & $\mathrm{S} 00^{\circ} 08.821$ & $\mathrm{E} 013^{\circ} 36.022$ \\
\hline & & Gab-2488 & $06 / 05 / 13$ & pos & $\mathrm{S} 00^{\circ} 08.790$ & $\mathrm{E} 013^{\circ} 38.036$ \\
\hline & & Gab-2489 & $06 / 05 / 13$ & pos & $\mathrm{S} 00^{\circ} 08.790$ & $\mathrm{E} 013^{\circ} 38.036$ \\
\hline & \multirow[t]{2}{*}{ MA-ID-077 } & Gab-0919 & $07 / 04 / 11$ & neg & $\mathrm{S}^{\circ} 0^{\circ} 08.046$ & $\mathrm{E} 013^{\circ} 36.073$ \\
\hline & & Gab-1301 & $02 / 12 / 11$ & pos & $\mathrm{S} 00^{\circ} 07.910$ & $\mathrm{E} 013^{\circ} 36.707$ \\
\hline
\end{tabular}


Table 2. Cont.

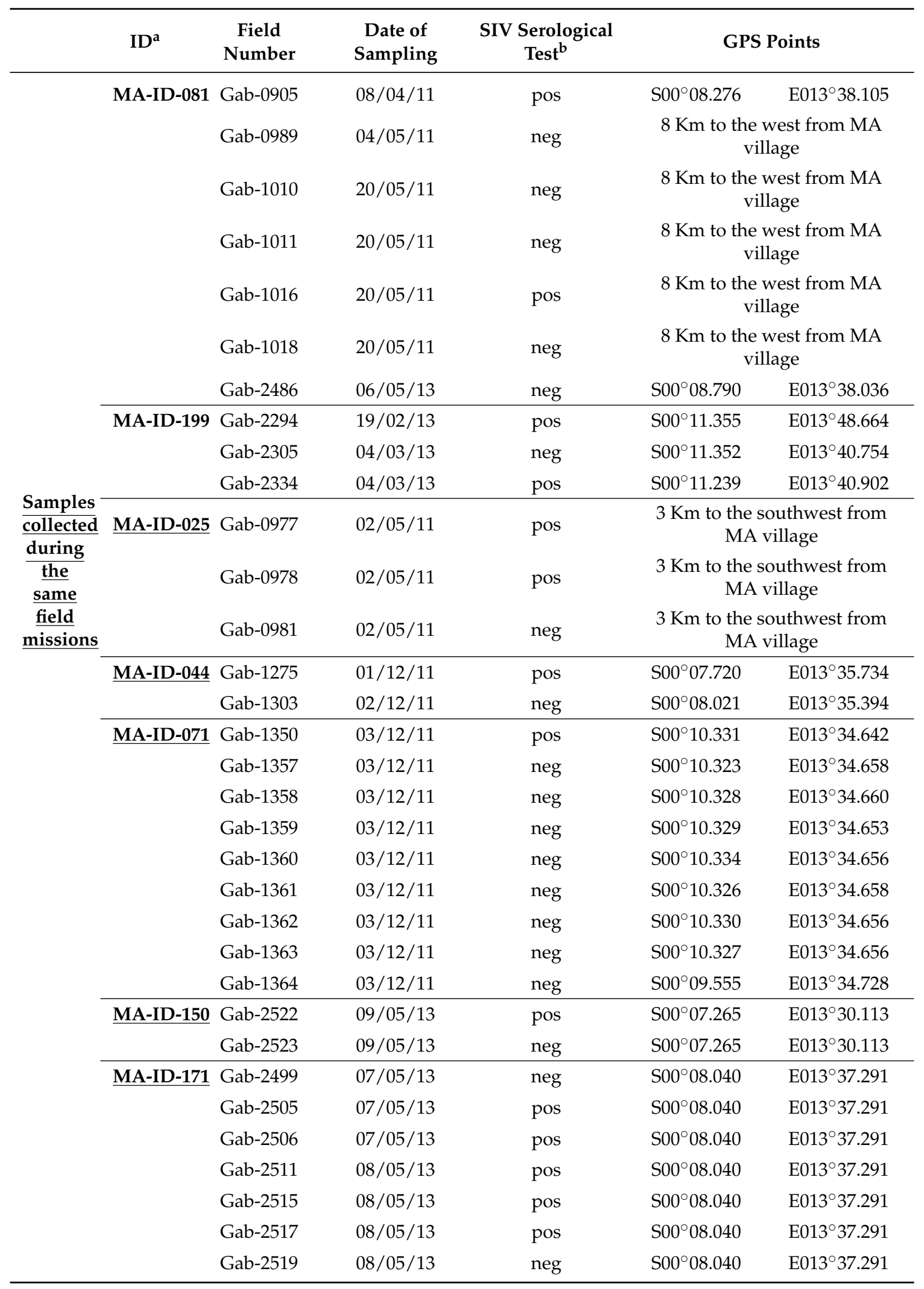

a Samples underligned have been collected during the same field mission; ${ }^{\mathrm{b}}$ neg $=$ negative sample, pos $=$ positive sample 


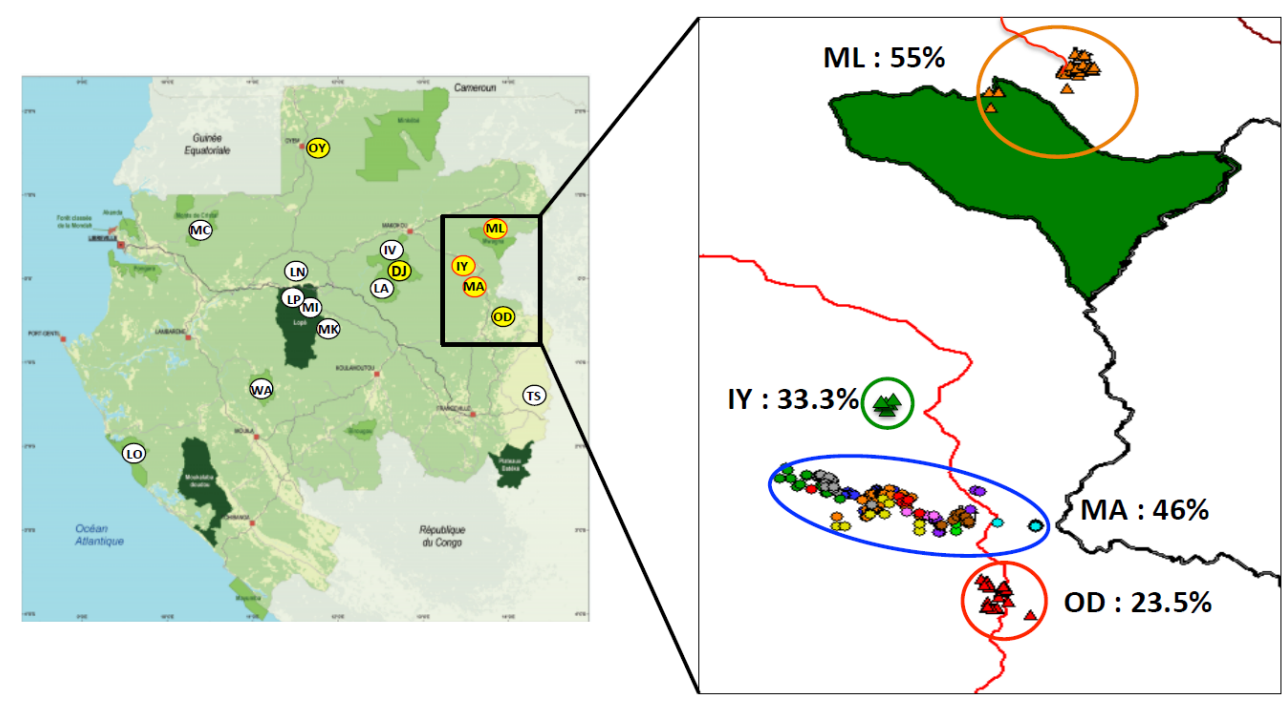

Figure 3. SIVcpz antibody positive samples from north-east Gabon. A/ Yellow circles with red perimeter represent sampling sites where SIVcpz have been PCR amplified. B/ details of SIVcpz positive sampling sites: colored circles correspond to the color codes used to represent the different SIVcpz identified in Figures 4 and 5: Blue $=$ MA, Green $=$ IY and Orange $=$ ML. Triangles correspond to SIVcpz antibody positive faecal samples collected in OD, IY and ML. Dots correspond to SIVcpz antibody positive faecal samples collected in MA. Prevalence based on serological tests is showed for each site. The trail linking Odjala to Malouma is represented by a red line. The green area corresponds to the different national parks. The site of DJ is not represented.

\subsection{Partial SIV pol, env and gp41-nef PCR Amplifications and Phylogenetic Analyses}

In order to confirm whether the animals with HIV-like antibodies were infected with SIV, we ran PCRs using generic and specific primers in the pol (150bp) and gp41 (170bp) regions of the genome. Among the 123 individuals, which displayed a HIV-like antibody positive profile, and which were collected at three different sites (MA, ML, and IY), we amplified partial pol and/or gp41 fragments in 29, five and one individual, respectively (Table 1). We also amplified pol and/or gp41 fragments in eight samples from MA and in five from ML, which did not display a complete microsatellite profile (Table 1). All PCR attempts performed on samples from DJ, OD and OY were unsuccessful.

In addition, we ran these PCRs on a subset of 146 faecal samples from MA displaying a HIV-like negative profile. Of 146 samples, we identified 50 individuals by microsatellite analysis and we amplified seven $\mathrm{pol}$ and/or gp 41 fragments, which represented $14 \%$ of infection rate with SIVcpz, whereas 23 out of 146 samples were non-interpretable by microsatellite analysis. However, we were able to amplify two SIVcpz fragments for two of them (Table 1). Altogether, using both pol and gp41 PCR protocols, we amplified 57 new SIVcpzPtt strains: 42 from genotyped chimpanzees and 15 from non-genotyped samples (Table 1). We also amplified a $916 \mathrm{bp}$ fragment covering the gp41 and the $5^{\prime}$ half part of nef gene, as well as a $365 \mathrm{pol}$ and a $325 \mathrm{bp}$ env fragment for 14 SIVcpz strains from MA and/or ML. Only five SIVcpz strains were amplified with the three PCR systems, whereas three strains were obtained with the pol and env PCR systems.

Phylogenetic analyses ran on nucleotide fragments of $150 \mathrm{bp}(\mathrm{pol})$ and of $170 \mathrm{bp}(\mathrm{gp} 41)$ showed that all new SIVcpzPtt strains obtained from the three sites (MA, IY and ML), formed a specific phylogeographic clade in both $\mathrm{pol}$ and gp 41 trees, within the SIVcpzPtt cluster. Interestingly, these newly isolated SIVcpzPtt strains were not closely related to the previously described SIVcpzGab-1, -2 and -4 except for SIVcpzGab1339, which clustered with SIVGab-2 in the pol phylogenetic tree (Figure 4).

Phylogenetic analyses ran on additional fragments of pol, env and gp41-nef, amplified in SIVcpz strains from MA and/or ML, showed that these newly obtained strains formed a highly supported 
clade (Figure 5). Moreover, all SIVcpzPtt sequences from ML branched within the SIVcpzPtt cluster of MA. Finally, the only SIVcpz strain (SIVcpzGab-2116-IYc-ID004) amplified from IY clustered at the root of the new SIVcpzGab clade in pol (Figure 4). SIVcpz-Gab985 and 1033-ID034 clustered with all other SIVcpz strains from MA in pol, whereas they were at the root of the new SIVcpzGab clade in the env phylogenetic tree. We failed to amplify larger fragments for these three SIVcpz strains; therefore we were unable to draw any conclusion about their possible recombination structure.
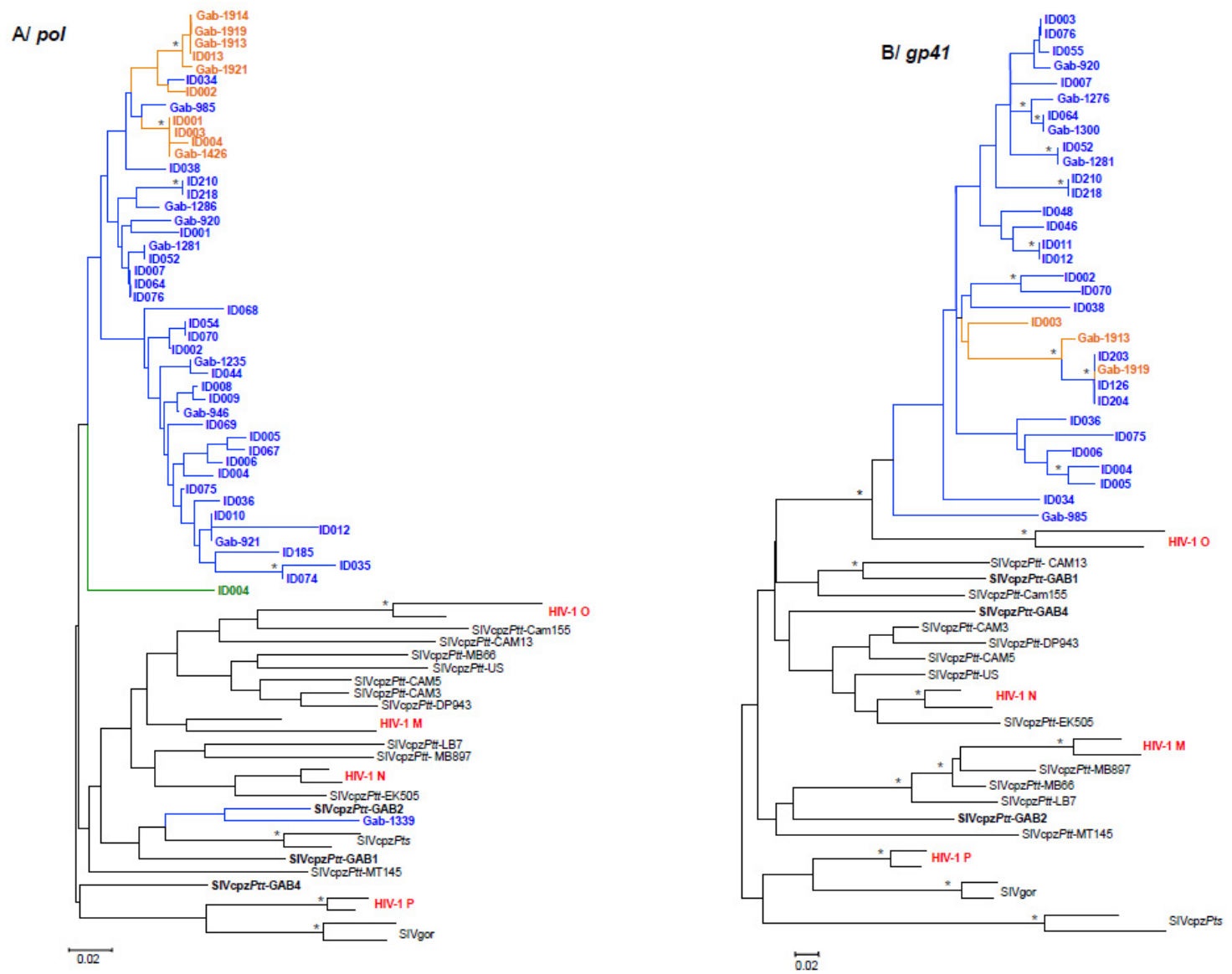

Figure 4. Phylogenetic analysis of partial pol (A) and gp41 (B) of the newly identified SIVcpz sequences from Gabon. New partial pol (150bp) and gp41 (170bp) SIVcpz-Gab sequences were compared to previously identified SIVcpzPtt and SIVcpzPts as well as HIV-1 goups M, N, O and P. Phylogenies were inferred using Neighbor-Joining method implemented in Mega 5 with the Kimura 2 Parameters model of evolution. Asterisks at nodes represent bootstraps values $\geqslant 70 \%$ (100 replicates). Scale bars indicate the number of base substitutions per site. New SIVcpz strains are colour-coded in accordance with figure 2B (MA in blue, ML in orange and IY in green). Strains amplified from genotyped animals are named using their ID number (IDXXX), whereas strains amplified from non-genotyped samples are named using the sample field number (GabXXXX). SIVcpzPtt-Gab-1, -2 and -4 are shown in bold. HIV-1 groups $\mathrm{M}, \mathrm{N}, \mathrm{O}$ and $\mathrm{P}$ are shown in red. 

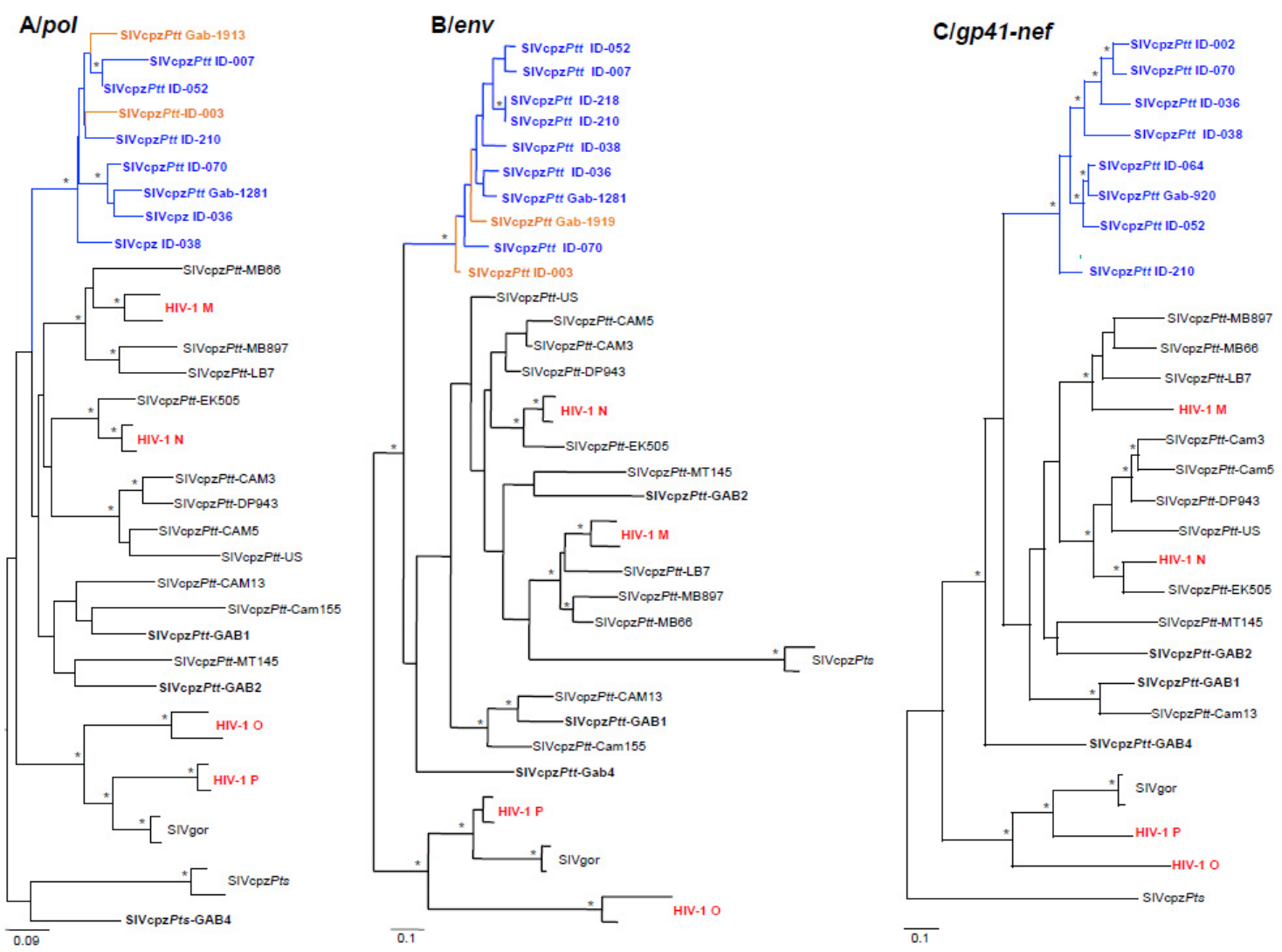

Figure 5. Phylogenetic analysis of partial pol (A), env (B) and gp41-nef (C) of the newly identified SIVcpz sequences from Gabon. New partial pol (365bp), env (325bp) and gp41-nef (916bp) SIVcpz-GAB sequences were compared to previously identified SIVcpzPtt and SIVcpzPts as well as HIV-1 goups M, N, O and P. Phylogenies were inferred using Maximum Likelihood methods implemented in PhyML under the GTR $+\Gamma_{4}+\mathrm{I}$ model of evolution. Asterisks at nodes represent bootstrap values $\geqslant 70 \%$ (1000 replicates). Scale bars indicate the number of base substitutions per site. New SIVcpz strains are colour-coded in accordance with figure 2B (MA in blue and ML in orange). Strains amplified from genotyped animals are named using their ID number (IDXXX), whereas strains amplified from non-genotyped samples are named using the sample field number (GabXXXX). SIVcpzPtt-Gab-1, -2 and -4 are shown in bold. HIV-1 groups $\mathrm{M}, \mathrm{N}, \mathrm{O}$ and $\mathrm{P}$ are shown in red.

\subsection{Vertical and Horizontal Transmission of SIV within and between Chimpanzee Communities}

\subsubsection{Allele Frequency Analysis}

On 859 analyzed samples, 649 (75.5\%) samples were successfully genotyped (Table 1). Allele frequency analysis on microsatellite results allowed us to identify 272 individuals (224-MA, 19-ML, 12-IY, 17-OD). Seven loci were typed, with a mean proportion of individuals typed of 0.97. Overall, the microsatellite loci used herein were highly polymorphic (mean polymorphic information content (PIC), 0.84), with a mean number of alleles per locus of 17.14, and an observed heterozygosity of 0.866 . The goodness-of-fit test showed that all selected loci were at Hardy-Weinberg (HW) equilibrium except for locus D2S1326. A deviation from HW equilibrium at a single locus may occur because of natural selection on a nearby gene. It can also be an indicator of problems in genotyping that locus: e.g., a segregating null allele, a failure to consistently distinguish alleles, biases towards typing particular genotypes, etc. Ideally the locus should be excluded from analysis; in practice minor deviations from HW equilibrium at one or two loci are unlikely to significantly bias likelihoods calculated across all loci [41]. Cervus did not detect the presence of null alleles. All frequencies 
of null alleles we obtained were close to zero or slightly negative (negative values imply an excess of observed heterozygote genotypes). Locus D4S243 had a slightly positive frequency $(+0.014)$. However, only with frequencies $>0.05$, it is advisable to exclude such a locus.

\subsubsection{Simulation of Parentage Analysis}

Simulations of parentage analysis reported that any candidate parent with a LOD score exceeding a critical value of 7.34 is assigned parentage with $95 \%$ confidence, and a LOD of 5.24 with a relaxed confidence of $80 \%$.

\subsubsection{Parentage Analysis}

Under a strict level of confidence (95\%), $22 \%$ of the individuals included in the analysis were assigned a candidate parent (expected rate: $10 \%$ ); under a relaxed level of confidence $(80 \%), 51 \%$ of the individuals were assigned a candidate parent (expected rate: $23 \%$ ).

For the purpose of this study, only those individuals who share an SIV infection, detected by serology and/or PCR tests, and a parental link have been further discussed. We identified ten couples of individuals infected with SIV who shared a parental link at 95\% confidence (Table S3). Among the individuals from the MA community, we found three pairs of males (ID-016 and ID-066; ID-031 and ID-066; ID-019 and ID-126), one pair of females (ID-003 and ID-077) and three male-female pairs (ID-059 and ID-063; ID-061 and ID-191; ID-132 and ID-210). Among the ML community we found three pairs of females sharing a parentage relation (ID-001 and ID-004; ID-003 and ID-006; ID-008). In addition, we also found a parental relation between a female from MA (ID-164) and a female from OD (ID-05). The female from OD did test negative for SIV. This is the only significant parental relationship that we found between communities.

A few of the above mentioned individuals had fragments of SIV successfully amplified. Phylogenetic trees of SIV pol and gp41 fragments (Figure 4) and of SIV pol, env, and gp41/nef (Figure 5) from SIV infected individuals/samples showed that strains of viruses infecting chimpanzees inhabiting the MA region (depicted in blue) are interspersed with a few strains infecting chimpanzees from ML (depicted in orange). Unfortunately, we were not able to genotype a few samples, which SIV fragments are included in the trees. Among the individuals with a parentage relation, only ML individuals ID-001 and ID-004 and MA individuals ID-210 and ID-132 are represented in the phylogenetic trees. The individual ID-004 collected in IY (depicted in green in Figure 4) bears no parental relation with any other individual whose viruses are represented in phylogenetic trees.

\section{Discussion}

To our knowledge, this is the first report on SIV infection in wild-living chimpanzees (Pan troglodytes troglodytes) from Gabon. The SIV infection rate varied from $0 \%$ to $55 \%$ with an overall prevalence of $26.1 \%$. Our data are consistent with previously documented rates from Cameroon and Tanzania [5,6]. In some locations, however, chimpanzees appeared not to be infected, as observed in some communities from Cameroon and Tanzania [5,6]. All the SIVcpz positive samples were collected north of the Ogooué River. To date, all SIVcpz positive samples isolated in west-central Africa have been found between the left bank of the Sanaga and the right bank of the Ogooué Rivers. The Ogooué River does not represent a genetic barrier for the subspecies of chimpanzee Pan troglodytes troglodytes, which is delimited instead by the Ubangi and the Congo River [21]. Little is known regarding the historical course and size of the Ogooué River, but rivers are known to change over time. Therefore, it is possible that at some point in time the river has lost (or acquired) the capacity of acting as a dispersal barrier. Exchange between chimpanzee populations might have been minimal at some point preventing SIV to cross the river [46-48]. Moreover, the relatively exiguous number of samples $(n=388)$ collected south of the Ogooué River does not allow us to be absolutely sure of the lack of SIV infection in chimpanzees living in these areas; additional studies are needed to confirm this. 
In the north of Gabon, only one sample of 78 collected has a SIV positive serology result but the viral RNA could not be amplified (Figure 1). Of note, one of the first SIVcpz (SIVcpz-Gab-1) was identified in a chimpanzee captured in this region [27], suggesting that this virus was circulating among chimpanzee populations in the 1980s-1990s. However, the number of samples collected in this region was not sufficient and additional studies are needed to determine whether this virus is still circulating in this area and at which prevalence.

In the northeast of Gabon instead, all the chimpanzee communities on the left bank of the Ivindo River were infected with SIVcpz. These animals live in a continuous forest block, delimited westward by the Ivindo, southward by the Ogooue River (Figure 1) and to the east by the Republic of Congo with the Sangha River as a principal natural barrier. The collection sites, except for Djidji (DJ), which is situated inside the Ivindo National Park on the left bank of the Ivindo River, are adjacent to the villages of Odjala (OD), Makatamangoye 2 (MA), Iyoko milieu (IY) and Malouma (ML) (Figure 3). Taking into account the number of individuals identified, the prevalence observed was $46 \%$ for MA and $63.5 \%$ for ML. However, the prevalence rate observed in ML was likely overestimated since we failed to obtain genotype in half of the samples. We found some discordance in the serology results, with some individuals being first sero-positive followed by samples, which became sero-negative. The lack of sensitivity of the serology test may be due to: (I) the presence of Antigen-antibody binding inhibitors in the faecal samples [49]; (II) the collection of a faecal sample later in the day, which could contain a lower titer of antibodies compared to the first morning defecation; (III) the degradation of the faecal material.

Besides, we obtained SIV RNA for only $23.4 \%$ of the specimens, which resulted SIV positive by INNO-LIA I/II score Confirmation test. This result could be due to either a low sensitivity of the molecular tools or a low viral load in faeces or to the natural clearance of the virus in the host. A contrario, in randomly selected SIV antibodies negative samples from MA, we succeeded in amplifying SIV fragments in $14 \%$ of them (Table 1). Altogether, these results suggest that we may have underestimated the SIV prevalence rate. It also highlights the importance of developing new serological and molecular tools for viral detection and characterization in faecal samples. A census made of chimpanzee populations throughout Gabon between December 1980 and February 1983 estimated $64,000 \pm 13,000$ animals living in the country [50]. This population has since decreased in number and density, due to Ebola virus outbreaks, diminished resources and habitat and human pressure and hunting [51]. Because it is difficult to follow non-habituated chimpanzees in the wild and collect consecutive samples, non-invasive sampling remains the preferred approach for these studies.

The phylogenetic analyses showed that the different SIV fragments amplified in pol and/or env, obtained from chimpanzees from MA, IY, and ML cluster together in phylogenetic trees, but are separate from the strains of SIVcpzPtt previously isolated in Cameroon and in Gabon (Figures 4 and 5). In fact, the position in the phylogeny of SIVcpzPtt-Gab-1, -2 and -4 varies according to the gene investigated. SIVcpzPtt-Gab-1, -2 and -4 are not linked to the new strains identified in this study, except for SIVcpz-Gab1339, isolated in a chimpanzee collected in MA, which gene pol was partially amplified. SIVcpz-Gab1339 is tightly linked to SIVcpz-Gab-2, isolated in a chimpanzee captured 30 years ago around the same village. Unfortunately, we were not able to amplify a larger fragment of its genome to study more in detail the phylogenetic similarities of the two strains. It is however surprising that only one of the strains partially amplified from MA is phylogenetically close to SIVcpz-Gab-2. Further research, i.e. the amplification of the full-length genome of SIVcpz-Gab1339 and of other strains circulating in that area is needed to know whether this new strain is the result of the recombination of old and extant strains, or whether SIVcpz-Gab-2 was a viral strain weakly represented or supplanted by the introduction of a new SIV in these chimpanzee communities. Of note, phylogenetic analyses of SIVcpzPtt-Gab-2 full-length genome suggested that this strain itself was the result of past recombination events [52]. 
Our results also demonstrated that there might be an ongoing viral exchange between communities. It is worth noting that, during the three field trips conducted in ML, we encountered only one group of chimpanzees estimated to be composed of about 30 to 40 adult individuals (adults and juveniles). This village is situated in an area, which has been hardly hit by several Ebola outbreaks in the early years 2000. This epidemic led to a catastrophic ape decline in Gabon and, more in general, in western equatorial Africa [53-55]. The genetic similarity between the SIV infecting this community and the SIV infecting chimpanzees from Makatamangoye 2 may be the result of the migration of infected chimpanzees from the south to the northern region of Malouma. We also showed that female chimpanzees can migrate from or to regions that are about $30 \mathrm{~km}$ apart, as reported for the mother-daughter pair ID-164 (MA) and ID-005 (OD). The phylogenetic trees analyses (Figures 4 and 5) showed closely related viruses that suggested potential epidemiologic links between the infected animals. Unrelated individuals sharing very similar viruses, demonstrate the spread of SIV via horizontal routes (due to sexual or aggressive behaviors, depending on the sexes involved). Related individuals like the MA pair male/female and the female/female pair from ML are testimony of possible vertical transmissions of the virus. A few more related individuals have been identified, if we consider the serology results as well, but because we do not have any molecular details about these strains, we cannot speculate about the viral transmission routes involved.

Therefore, in order to better understand the spread dynamic of SIV within and between ape's communities, it would be necessary to complete the host genetic profiles from infected and non-infected individuals, to amplify SIV fragments from more samples that tested positive for Antibodies, and to complete genomes.

Altogether, our data showed that there is a high prevalence of SIV infection in chimpanzee communities living in the northeast of Gabon and a high genetic diversity of the circulating SIVcpz strains with at least four distinct clades. Previous studies showed that SIV infection in eastern chimpanzees had a negative impact on their health and reproduction [12]. In central Africa, only wild born chimpanzee held captive showed signs of an AIDS-like disease [13,14]. Thus, the impact of such infection in wild chimpanzees from west central Africa needs to be further evaluated.

The human populations living along the Odjala-Malouma road axe have access to the forest, and bushmeat is their main source of animal proteins. Chimpanzees are hunted for meat, although in smaller proportions compared to other mammals [56]. Given the high prevalence of SIV detected in the region, the risk of transmission to the human population should not be ignored. In fact, this region represents a hot-spot for a potential emergence of a new Human Immunodeficiency Virus.

\section{Conclusion}

Our work showed for the first time a high rate of SIVcpz infection in wild-living chimpanzee communities from northeastern Gabon. Previous studies, led by our research team, discovered the origin of the four HIV-1 groups known to date from chimpanzees and gorillas inhabiting the Cameroonian rain forest [1-4,7]. The majority of faecal samples analyzed in this study have been collected less than $20 \mathrm{~km}$ away from villages. This area of Gabon is relatively remote and people depend on forest resources for living. Although it is difficult to estimate the number of chimpanzees hunted per year, the informal discussions we had with the villagers suggested that this practice is not rare. In this context, the establishment of sentinel surveillance among human populations would be helpful to anticipate the potential emergence of a new Human Immunodeficiency Virus.

Acknowledgments: This work was supported in part by the Centre International de Recherches Médicales de Franceville (CIRMF), the Institut de Recherche pour le Développement (IRD) and by grants from the National Institute of Health (RO1 AI 50529), the Agence Nationale de Recherches sur le SIDA (ANRS 12255) and the Agence Nationale de la Recherche (ANR JCJC ORIGIN 2012). We thank the Ministry of Water and Forests of Gabon. We thank Martine Koné for her collaboration and participation in this study. Vanina Boué was supported by a Ph.D grant from Sidaction.

Author Contributions: Conceived and designed the experiments: Florian Liégeois, Vanina Boué, François Rouet, Sabrina Locatelli. Performed the experiments: Florian Liégeois, Vanina Boué, Floriane Boucher, 
Ahidjo Ayouba, Christelle Butel, Amandine Esteban, Alain-Prince Okouga, Alphonse Ngoundouet, Paul Ngari. Analyzed the data: Florian Liégeois, Floriane Boucher, Vanina Boué, Sabrina Locatelli. Contributed reagents/materials/analysis tools: Florian Liégeois, Vanina Boué, Sabrina Locatelli. Wrote the paper: Florian Liégeois, Vanina Boué, Sabrina Locatelli, François Rouet. Study conducted in the field: Florian Liégeois, Vanina Boué, Floriane Boucher, Alain-Prince Okouga, Alphonse Ngoundouet, Franck Prugnolle, Benjamin Ollomo, Peggy Motsch, Guillaume Le Flohic.

Conflicts of Interest: The authors declare no conflict of interest.

Supplementary Materials: Supplementary materials can be found at http://www.mdpi.com/1999-4915/ 7/9/2855/s1.

\section{References}

1. Keele, B.F.; Van Heuverswyn, F.; Li, Y.; Bailes, E.; Takehisa, J.; Santiago, M.L.; Bibollet-Ruche, F.; Chen, Y.; Wain, L.V.; Liegeois, F.; et al. Chimpanzee reservoirs of pandemic and nonpandemic HIV-1. Science 2006, 313, 523-526. [CrossRef] [PubMed]

2. Van Heuverswyn, F.; Li, Y.; Neel, C.; Bailes, E.; Keele, B.F.; Liu, W.; Loul, S.; Butel, C.; Liegeois, F.; Bienvenue, Y.; et al. Human immunodeficiency viruses: SIV infection in wild gorillas. Nature 2006, 444, 164-164. [CrossRef] [PubMed]

3. D'Arc, M.; Ayouba, A.; Esteban, A.; Learn, G.H.; Boue, V.; Liegeois, F.; Etienne, L.; Tagg, N.; Leendertz, F.H.; Boesch, C.; et al. Origin of the HIV-1 group O epidemic in western lowland gorillas. Proc. Natl. Acad. Sci. USA 2015, 112, E1343-E1352. [CrossRef] [PubMed]

4. Etienne, L.; Locatelli, S.; Ayouba, A.; Esteban, A.; Butel, C.; Liegeois, F.; Aghokeng, A.; Delaporte, E.; Mpoudi Ngole, E.; Peeters, M. Noninvasive follow-up of Simian Immunodeficiency Virus infection in wild-living nonhabituated western lowland gorillas in Cameroon. J. Virol. 2012, 86, 9760-9772. [CrossRef] [PubMed]

5. Van Heuverswyn, F.; Li, Y.; Bailes, E.; Neel, C.; Lafay, B.; Keele, B.F.; Shaw, K.S.; Takehisa, J.; Kraus, M.H.; Loul, S.; et al. Genetic diversity and phylogeographic clustering of SIVcpzPtt in wild chimpanzees in Cameroon. Virology 2007, 368, 155-171. [CrossRef] [PubMed]

6. Rudicell, R.S.; Piel, A.K.; Stewart, F.; Moore, D.L.; Learn, G.H.; Li, Y.; Takehisa, J.; Pintea, L.; Shaw, G.M.; Moore, J.; et al. High prevalence of Simian Immunodeficiency Virus infection in a community of savanna chimpanzees. J. Virol. 2011, 85, 9918-9928. [CrossRef] [PubMed]

7. Neel, C.; Etienne, L.; Li, Y.; Takehisa, J.; Rudicell, R.S.; Bass, I.N.; Moudindo, J.; Mebenga, A.; Esteban, A.; Van Heuverswyn, F.; et al. Molecular epidemiology of Simian Immunodeficiency Virus infection in wild-living gorillas. J. Virol. 2010, 84, 1464-1476. [CrossRef] [PubMed]

8. Rudicell, R.S.; Holland Jones, J.; Wroblewski, E.E.; Learn, G.H.; Li, Y.; Robertson, J.D.; Greengrass, E.; Grossmann, F.; Kamenya, S.; Pintea, L.; et al. Impact of Simian Immunodeficiency Virus infection on chimpanzee population dynamics. PLoS Pathog. 2010, 6, e1001116. [CrossRef] [PubMed]

9. Locatelli, S.; McKean, K.A.; Sesink Clee, P.R.; Gonder, M.K. The evolution of resistance to Simian Immunodeficiency Virus (SIV): A review. Int. J. Primatol. 2014, 35, 349-375. [CrossRef]

10. Locatelli, S.; Peeters, M. Cross-species transmission of Simian Retroviruses: How and why they could lead to the emergence of new diseases in the human population. AIDS 2012, 26, 659-673. [CrossRef] [PubMed]

11. Pandrea, I.; Apetrei, C. Where the wild things are: Pathogenesis of SIV infection in African nonhuman primate hosts. Curr. HIV/AIDS Rep. 2010, 7, 28-36. [CrossRef] [PubMed]

12. Keele, B.F.; Jones, J.H.; Terio, K.A.; Estes, J.D.; Rudicell, R.S.; Wilson, M.L.; Li, Y.; Learn, G.H.; Beasley, T.M.; Schumacher-Stankey, J.; et al. Increased mortality and AIDS-like immunopathology in wild chimpanzees infected with SIVcpz. Nature 2009, 460, 515-519. [CrossRef] [PubMed]

13. Etienne, L.; Nerrienet, E.; LeBreton, M.; Bibila, G.T.; Foupouapouognigni, Y.; Rousset, D.; Nana, A.; Djoko, C.F.; Tamoufe, U.; Aghokeng, A.F.; et al. Characterization of a new Simian Immunodeficiency Virus strain in a naturally infected Pan troglodytes troglodytes chimpanzee with AIDS related symptoms. Retrovirology 2011, 8. [CrossRef]

14. Schmidt, F.; Greenwood, E.J.D.; Nagel, M.; Herbert, A.; Liégeois, F.; Mouinga-Ondémé, A.; Peeters, M.; Sica, J.; Oloussou, D.; Heeney, J.L.; et al. ARV treatment of a naturally SIVcpz infected and disease progressing Pan troglodytes troglodytes Chimpanzee shows clinical and immunovirological efficiency. In 38th Annual Meeting on Retroviruses, Cold Spring Harbor Laboratory, NY, USA, 20-25 May 2013. 
15. Joint United Nations Programme on HIV / AIDS (UNAIDS). Unaids report on the global aids epidemic 2013, 2013.

16. Simon, F.; Mauclere, P.; Roques, P.; Loussert-Ajaka, I.; Muller-Trutwin, M.C.; Saragosti, S.; Georges-Courbot, M.C.; Barre-Sinoussi, F.; Brun-Vezinet, F. Identification of a new Human Immunodeficiency Virus type 1 distinct from group $\mathrm{M}$ and group O. Nat. Med. 1998, 4, 1032-1037. [CrossRef] [PubMed]

17. Plantier, J.C.; Leoz, M.; Dickerson, J.E.; De Oliveira, F.; Cordonnier, F.; Lemee, V.; Damond, F.; Robertson, D.L.; Simon, F. A new Human Immunodeficiency Virus derived from gorillas. Nat. Med. 2009, 15, 871-872. [CrossRef] [PubMed]

18. Liegeois, F.; Boue, V.; Butel, C.; Mouinga-Ondeme, A.; Sica, J.; Zamba, C.; Peeters, M.; Delaporte, E.; Rouet, F. HIV type-1 group $\mathrm{O}$ infection in gabon: Low prevalence rate but circulation of genetically diverse and drug-resistant HIV type-1 group O strains. AIDS Res. Hum. Retroviruses 2013, 29, 1085-1090. [CrossRef] [PubMed]

19. Vessiere, A.; Rousset, D.; Kfutwah, A.; Leoz, M.; Depatureaux, A.; Simon, F.; Plantier, J.C. Diagnosis and monitoring of HIV-1 group O-infected patients in cameroun. J. Acquir. Immune Defic. Syndr. 2010, 53, 107-110. [CrossRef] [PubMed]

20. Hemelaar, J. The origin and diversity of the HIV-1 pandemic. Trends Mol. Med. 2012, 18, 182-192. [CrossRef] [PubMed]

21. Groves, C. Smithsonian series in comparative evolutionary biology. In Primate taxonomy; Smithsonian Institution Press: Washington D.C., WA, USA, 2001.

22. Sharp, P.M.; Shaw, G.M.; Hahn, B.H. Simian Immunodeficiency Virus infection of chimpanzees. J. Virol. 2005, 79, 3891-3902. [CrossRef] [PubMed]

23. Leendertz, S.A.; Locatelli, S.; Boesch, C.; Kucherer, C.; Formenty, P.; Liegeois, F.; Ayouba, A.; Peeters, M.; Leendertz, F.H. No evidence for transmission of SIVwrc from western red colobus monkeys (Piliocolobus badius badius) to wild west african chimpanzees (Pan troglodytes verus) despite high exposure through hunting. BMC Microbiol. 2011, 11. [CrossRef] [PubMed]

24. Prince, A.M.; Brotman, B.; Lee, D.H.; Andrus, L.; Valinsky, J.; Marx, P. Lack of evidence for HIV type 1-related SIVcpz infection in captive and wild chimpanzees (Pan troglodytes verus) in West Africa. AIDS Res. Hum. Retroviruses 2002, 18, 657-660. [CrossRef] [PubMed]

25. Oates, J.F.; Groves, C.P.; Jenkins, P.D. The type locality of Pan troglodytes vellerosus (gray, 1862), and implications for the nomenclature of West African chimpanzees. Primates 2009, 50, 78-80. [CrossRef] [PubMed]

26. Li, Y.; Ndjango, J.B.; Learn, G.H.; Ramirez, M.A.; Keele, B.F.; Bibollet-Ruche, F.; Liu, W.; Easlick, J.L.; Decker, J.M.; Rudicell, R.S.; et al. Eastern Chimpanzees, but not bonobos, represent a simian immunodeficiency virus reservoir. J. Virol. 2012, 86, 10776-10791. [CrossRef] [PubMed]

27. Peeters, M.; Honore, C.; Huet, T.; Bedjabaga, L.; Ossari, S.; Bussi, P.; Cooper, R.W.; Delaporte, E. Isolation and partial characterization of an HIV-related virus occurring naturally in chimpanzees in Gabon. AIDS 1989, 3, 625-630. [CrossRef] [PubMed]

28. Huet, T.; Cheynier, R.; Meyerhans, A.; Roelants, G.; Wain-Hobson, S. Genetic organization of a chimpanzee lentivirus related to HIV. Nature 1990, 345, 356-359. [CrossRef] [PubMed]

29. Souquiere, S.; Makuwa, M.; Salle, B.; Kazanji, M. New strain of Simian Immunodeficiency Virus identified in wild-born chimpanzees from Central Africa. PLoS ONE 2012, 7, e44298. [CrossRef] [PubMed]

30. Liegeois, F.; Boue, V.; Mouacha, F.; Butel, C.; Ondo, B.M.; Pourrut, X.; Leroy, E.; Peeters, M.; Rouet, F. New STLV-3 strains and a divergent SIVmus strain identified in non-human primate bushmeat in Gabon. Retrovirology 2012, 9, 28. [CrossRef] [PubMed]

31. Liegeois, F.; Schmidt, F.; Boue, V.; Butel, C.; Mouacha, F.; Ngari, P.; Ondo, B.M.; Leroy, E.; Heeney, J.L.; Delaporte, E.; et al. Full-length genome analyses of two new Simian Immunodeficiency Virus (SIV) strains from mustached monkeys (C. Cephus) in Gabon illustrate a complex evolutionary history among the SIVmus/mon/gsn lineage. Viruses 2014, 6, 2880-2898. [CrossRef] [PubMed]

32. Fouchet, D.; Verrier, D.; Ngoubangoye, B.; Souquiere, S.; Makuwa, M.; Kazanji, M.; Gonzalez, J.P.; Pontier, D. Natural Simian Immunodeficiency Virus transmission in mandrills: A family affair? Proc. Biol. Sci. 2012, 279, 3426-3435. [CrossRef] [PubMed] 
33. Souquiere, S.; Bibollet-Ruche, F.; Robertson, D.L.; Makuwa, M.; Apetrei, C.; Onanga, R.; Kornfeld, C.; Plantier, J.C.; Gao, F.; Abernethy, K.; et al. Wild Mandrillus sphinx are carriers of two types of lentivirus. J. Virol. 2001, 75, 7086-7096. [CrossRef] [PubMed]

34. Peeters, M.; Courgnaud, V.; Abela, B.; Auzel, P.; Pourrut, X.; Bibollet-Ruche, F.; Loul, S.; Liegeois, F.; Butel, C.; Koulagna, D.; et al. Risk to human health from a plethora of Simian Immunodeficiency Viruses in primate bushmeat. Emerg. Infect. Dis. 2002, 8, 451-457. [CrossRef] [PubMed]

35. Boom, R.; Sol, C.J.; Salimans, M.M.; Jansen, C.L.; Wertheim-van Dillen, P.M.; van der Noordaa, J. Rapid and simple method for purification of nucleic acids. J. Clin. Microbiol. 1990, 28, 495-503. [PubMed]

36. Van der Kuyl, A.C.; Dekker, J.T.; Goudsmit, J. Primate genus Miopithecus: Evidence for the existence of species and subspecies of dwarf guenons based on cellular and endogenous viral sequences. Mol. Phylogenet. Evol. 2000, 14, 403-413. [CrossRef] [PubMed]

37. Kocher, T.D.; Thomas, W.K.; Meyer, A.; Edwards, S.V.; Paabo, S.; Villablanca, F.X.; Wilson, A.C. Dynamics of mitochondrial DNA evolution in animals: Amplification and sequencing with conserved primers. Proc. Natl. Acad. Sci. USA 1989, 86, 6196-6200. [CrossRef] [PubMed]

38. National Librairy of Medicine Basic local alignment search tools. Available online: http://blast.ncbi.nlm.nih. gov / Blast.cgi (accessed on 15 November 2014).

39. Sullivan, K.M.; Mannucci, A.; Kimpton, C.P.; Gill, P. A rapid and quantitative DNA sex test: Fluorescence-based PCR analysis of X-Y homologous gene amelogenin. Biotechniques 1993, 15, 636-638. [PubMed]

40. Bonin, A.; Bellemain, E.; Bronken Eidesen, P.; Pompanon, F.; Brochmann, C.; Taberlet, P. How to track and assess genotyping errors in population genetics studies. Mol. Ecol. 2004, 13, 3261-3273. [CrossRef] [PubMed]

41. Kalinowski, S.T.; Taper, M.L.; Marshall, T.C. Revising how the computer program cervus accommodates genotyping error increases success in paternity assignment. Mol. Ecol. 2007, 16, 1099-1106. [CrossRef] [PubMed]

42. Vigilant, L.; Guschanski, K. Using genetics to understand the dynamics of wild primate populations. Primates 2009, 50, 105-120. [CrossRef] [PubMed]

43. Tamura, K.; Peterson, D.; Peterson, N.; Stecher, G.; Nei, M.; Kumar, S. Mega5: Molecular evolutionary genetics analysis using maximum likelihood, evolutionary distance, and maximum parsimony methods. Mol. Biol. Evol. 2011, 28, 2731-2739. [CrossRef] [PubMed]

44. Guindon, S.; Dufayard, J.F.; Lefort, V.; Anisimova, M.; Hordijk, W.; Gascuel, O. New algorithms and methods to estimate maximum-likelihood phylogenies: Assessing the performance of phyml 3.0. Syst. Biol. 2010, 59, 307-321. [CrossRef] [PubMed]

45. Milne, I.; Lindner, D.; Bayer, M.; Husmeier, D.; McGuire, G.; Marshall, D.F.; Wright, F. Topali v2: A rich graphical interface for evolutionary analyses of multiple alignments on hpc clusters and multi-core desktops. Bioinformatics 2009, 25, 126-127. [CrossRef] [PubMed]

46. Mitchell, M.W.; Locatelli, S.; Sesink Clee, P.R.; Thomassen, H.A.; Gonder, M.K. Environmental variation and rivers govern the structure of chimpanzee genetic diversity in a biodiversity hotspot. BMC Evol. Biol. 2015, 15. [CrossRef] [PubMed]

47. Telfer, P.T.; Souquiere, S.; Clifford, S.L.; Abernethy, K.A.; Bruford, M.W.; Disotell, T.R.; Sterner, K.N.; Roques, P.; Marx, P.A.; Wickings, E.J. Molecular evidence for deep phylogenetic divergence in Mandrillus sphinx. Mol. Ecol. 2003, 12, 2019-2024. [CrossRef] [PubMed]

48. Anthony, N.M.; Johnson-Bawe, M.; Jeffery, K.; Clifford, S.L.; Abernethy, K.A.; Tutin, C.E.; Lahm, S.A.; White, L.J.; Utley, J.F.; Wickings, E.J.; et al. The role of pleistocene refugia and rivers in shaping gorilla genetic diversity in Central Africa. Proc. Natl. Acad. Sci. USA 2007, 104, 20432-20436. [CrossRef] [PubMed]

49. Locatelli, S.; Liegeois, F.; Lafay, B.; Roeder, A.D.; Bruford, M.W.; Formenty, P.; Noe, R.; Delaporte, E.; Peeters, M. Prevalence and genetic diversity of Simian Immunodeficiency Virus infection in wild-living red colobus monkeys (Piliocolobus badius badius) from the Taï forest, Côte d'Ivoire: SIVwrc in wild-living western red colobus monkeys. Infect. Genet. Evol. 2008, 8, 1-14. [CrossRef] [PubMed]

50. Tutin, C.; Fernandez, M. Nationwide census of gorilla (Gorilla gorilla gorilla) and chimpanzee (Pan troglodytes troglodytes) populations in Gabon. Am. J. Primatol. 1984, 6, 313-336. [CrossRef]

51. IUCN. Red list of threatened species. Available online: http://www.iucnredlist.org (accessed on 30 March 2015). 
52. Bibollet-Ruche, F.; Gao, F.; Bailes, E.; Saragosti, S.; Delaporte, E.; Peeters, M.; Shaw, G.M.; Hahn, B.H.; Sharp, P.M. Complete genome analysis of one of the earliest SIVcpzPtt strains from Gabon (SIVcpzGab-2). AIDS Res. Hum. Retroviruses 2004, 20, 1377-1381. [CrossRef] [PubMed]

53. Bermejo, M.; Rodriguez-Teijeiro, J.D.; Illera, G.; Barroso, A.; Vila, C.; Walsh, P.D. Ebola outbreak killed 5000 gorillas. Science 2006, 314, 1564. [CrossRef] [PubMed]

54. Walsh, P.D.; Abernethy, K.A.; Bermejo, M.; Beyers, R.; De Wachter, P.; Akou, M.E.; Huijbregts, B.; Mambounga, D.I.; Toham, A.K.; Kilbourn, A.M.; et al. Catastrophic ape decline in Western Equatorial Africa. Nature 2003, 422, 611-614. [CrossRef] [PubMed]

55. Leroy, E.M.; Rouquet, P.; Formenty, P.; Souquiere, S.; Kilbourne, A.; Froment, J.M.; Bermejo, M.; Smit, S.; Karesh, W.; Swanepoel, R.; et al. Multiple ebola virus transmission events and rapid decline of Central African wildlife. Science 2004, 303, 387-390. [CrossRef] [PubMed]

56. Fa, J.E.; Ryan, S.F.; Bell, D.J. Hunting vulnerability, ecological charasteristics and harvest rates of buschmeat species in afrotropical forest. Biol. Conserv. 2005, 121, 167-176. [CrossRef]

(C) 2015 by the authors; licensee MDPI, Basel, Switzerland. This article is an open access article distributed under the terms and conditions of the Creative Commons by Attribution (CC-BY) license (http://creativecommons.org/licenses/by/4.0/). 